\title{
AS CONFIGURAÇÕES DO TRABALHO REMOTO DA CATEGORIA DOCENTE NO CONTEXTO DA PANDEMIA COVID- 19
}

\author{
The remote work settings of teacher's category in the context of pandemic \\ Covid- 19
}

\author{
Kelen Aparecida da Silva Bernardo' \\ Fernanda Landolfi Maia ${ }^{2}$ \\ Maria Aparecida Bridi ${ }^{3}$
}

\section{Resumo}

0 trabalho docente, em todos os níveis de ensino, nas instituições públicas e privadas brasileiras está passando por um dos grandes desafios dos últimos tempos: o ensino remoto. Com a pandemia da COVID-19, o ano de 2020 tornou-se o cenário mundial das urgências e tomadas de decisões com um objetivo central: o da tentativa de evitar a propagação do vírus. No Brasil, em atendimento às recomendações da Organização Mundial da Saúde de isolamento social, o Ministério da Educação, por meio das portarias $n^{\circ} 343$ e $n^{\circ} 345$, autorizou a implantação do Ensino Remoto Emergencial (ERE) que permite que disciplinas ministradas na modalidade presencial sejam realizadas de maneira virtualmente por meio de plataformas digitais. Com base nesse cenário este artigo tem por finalidade apresentar dados da pesquisa intitulada "0 trabalho remoto/ home-office no contexto da COVID-19" com o foco nas condições objetivas de trabalho dos professores nesse contexto. A metodologia é composta por uma pesquisa de natureza exploratória, que foi realizada por meio de um questionário aplicado pela plataforma Google Forms e contou com 37 perguntas, sendo duas delas, questões abertas, com um total de 262 de respondentes. Os principais resultados demonstram que os docentes foram submetidos ao processo de intensificação do trabalho, flexibilização das atividades e alterações na organização do trabalho dos professores.

\footnotetext{
I Graduada em Serviço Social e Mestre em Ciências Sociais Aplicadas pela Universidade Estadual de Ponta Grossa (UEPG). Doutora em Sociologia pela Universidade Federal do Paraná, membro do Grupo de Estudos e Pesquisa Trabalho e Sociedade (GETS/UFPR). Pesquisadora da Rede de Estudos e Monitoramento Interdisciplinar da Reforma Trabalhista (REMIR). Pesquisadora das temáticas flexibilização e intensificação do trabalho docente. E-mail: kelenbernardo18@gmail.com Cidade de trabalho: Ponta Grossa/PR.

2 Doutora em Sociologia, Mestre em Educação, Cientista Social e Secretária Executiva. Professora do Setor de Educação Profissional e Tecnológica da Universidade Federal do Paraná (UFPR), membro do Grupo de Estudos e Pesquisa Trabalho e Sociedade (GETS/UFPR) e coordenadora do Grupo de Estudos e Pesquisa sobre o Secretariado (GEPSEC/UFPR). Pesquisadora da rede de estudos e monitoramento Interdisciplinar da reforma trabalhista (REMIR). Pesquisadora das temáticas de intensificação, flexibilização e reconfigurações do trabalho docente. E-mail: fernanda.landolfi@gmail.com Cidade de trabalho: Curitiba/PR.

3 Socióloga, professora do Departamento de Sociologia (DECISO) e do Programa de Pós-Graduação em Sociologia na Universidade Federal do Paraná (UFPR). Vice-Presidente da Associação Brasileira de Estudos do Trabalho (ABET) no período 2020-2021; Pesquisadora da Rede de Estudos e Monitoramento Interdisciplinar da Reforma Trabalhista (REMIR). Coeditora da Revista da ABET. Autora de livros, capítulos de livros e de artigos em revistas científicas. E-mail: macbridi@gmail.com Cidade de trabalho: Curitiba/PR.
} 
As configurações do trabalho remoto da categoria docente no contexto da pandemia covid-19 |

Kelen Aparecida da Silva Bernardo | Fernanda Landolfi Maia \& Maria Aparecida Bridi

Palavras-chave: Condições do trabalho docente; Trabalho remoto; Isolamento social.

Abstract

Teaching work, at all levels of education, in Brazilian public and private institutions is experiencing one of the great challenges of recent times: remote education. With the pandemic of COVID-19, the year 2020 became the world scene of urgencies and decision-making with a central objective: that of trying to prevent the spread of the virus. In Brazil, in compliance with the recommendations of the World Health Organization for social isolation, the Ministry of Education, through ordinances 343 and no. 345, authorized the implementation of Emergency Remote Education (ERE) that allows disciplines taught in person to be carried out virtually through digital platforms. Based on this scenario, this article aims to present data from the research entitled "Remote work / home-office in the context of COVID19 " with a focus on the objective working conditions of teachers in this context. The methodology consists of an applied and exploratory research, which was applied through a questionnaire applied by the Google Forms platform and had 37 questions, two of which were open questions, with a total of 262 respondents. The main results show that teachers were subjected to the process of intensifying work, making activities more flexible and changes in the organization of teachers' work.

Keywords: Teaching work conditions; Remote work; Social isolation.

\section{Introdução}

O cenário mundial impactado pela pandemia da COVID-19 afetou política, social e economicamente a sociedade como um todo. Devido à facilidade de transmissão e ausência de vacina, a Organização Mundial de Saúde (OMS) recomendou o distanciamento social como medida de prevenção de contágio pela COVID-19. Assim, diferentes setores e instituições adotaram o trabalho remoto como alternativa de manutenção de parte de suas atividades. Desta forma, o trabalho remoto (home office), como uma modalidade do chamado teletrabalho, no contexto da pandemia se deu de forma emergencial, sem tempo para planejamento e preparação prévia dos trabalhadores envolvidos nesse processo.

A área da educação também foi uma das mais afetadas, visto que a sala de aula se constitui em espaço de aglomeração, situação a ser evitada de modo prioritário. As instituições educacionais suspenderam suas atividades presenciais como medida para evitar o contágio, em cumprimento às portarias n ${ }^{\circ} 343$ e $n^{\circ} 345$ do Ministério da Educação (BRASIL, 2020b; 2020c), buscando ofertar atividades para seus alunos a partir do Ensino Remoto Emergencial (ERE). O processo de mudança das atividades 
As configurações do trabalho remoto da categoria docente no contexto da pandemia covid-19 |

Kelen Aparecida da Silva Bernardo | Fernanda Landolfi Maia \& Maria Aparecida Bridi

presenciais nas instituições de ensino para a forma remota exigiu adaptações e aquisições de novas habilidades para todos os envolvidos no processo de ensino e aprendizagem. No que tange ao trabalho dos docentes, observam-se significativas mudanças quanto a forma de realizá-lo, demandando aos professores e professoras, além dos saberes necessários à prática docente, os conhecimentos telemáticos (softwares, computadores, plataformas digitais, entre outras).

Com o intuito de analisar as condições de trabalho dos docentes, em razão da mudança do trabalho presencial para o remoto, estabeleceu-se um recorte no banco de dados da pesquisa "O trabalho remoto/home-office no contexto da COVID-19". A referida pesquisa, de abrangência nacional, contemplou 906 participantes de diversos setores, sendo que 262 respondentes, ou seja, 28,9\% do total dos participantes, declararam ser do setor educacional, sendo a maioria absoluta de professores. Assim, a partir dos dados referentes ao setor educacional e da percepção dos professores e professoras, o presente artigo busca analisar as condições gerais de trabalho, o perfil, as características do trabalho $\mathrm{e}$ as dificuldades enfrentadas nessa modalidade de trabalho. Os resultados da pesquisa mostram que a adaptação desses trabalhadores quanto à mudança do trabalho presencial para o trabalho realizado no espaço doméstico, levou a processos de mais intensificação, a dificuldades de separação da vida privada da profissional, na medida em que todo o tempo passou a ser tempo de trabalho. Este artigo, além da introdução, contempla seções que se dividem em perspectiva teórico-metodológica, resultados e dados e considerações finais.

\section{Perspectivas teórico-metodológica e perfil dos docentes entrevistados}

Do ponto do percurso metodológico trata-se de uma pesquisa de natureza aplicada e exploratória, pois busca conhecer as condições e relações de trabalho dos docentes na modalidade remota devido ao isolamento social forçado pela pandemia da COVID-19. Para tanto, parte-se da pesquisa "O trabalho remoto/ home office no contexto da COVID-19" 
As configurações do trabalho remoto da categoria docente no contexto da pandemia covid-19 |

Kelen Aparecida da Silva Bernardo | Fernanda Landolfi Maia \& Maria Aparecida Bridi

realizada por pesquisadores do Grupo de Estudo Trabalho e Sociedade (GETs/UFPR) e a Rede de Estudos e Monitoramento Interdisciplinar da Reforma Trabalhista (REMIR) 4 que foi aplicada por meio de um questionário respondido pela plataforma Google Forms no período entre os dias 05 a $17 \mathrm{de}$ maio de 2020 e contou com 37 perguntas, sendo duas delas, questões abertas. A partir da organização e categorização das informações, foram selecionados somente aqueles que declararam pertencerem ao setor educacional, assim nomeado, porque além de docentes, também responderam à pesquisa pedagogos e gestores da educação. Os dados trazidos neste texto, refere-se aos 262 respondentes da pesquisa, em sua maioria professores.

Em relação ao perfil dos respondentes, ou seja, dos 262 participantes da pesquisa, a maioria é do sexo feminino (67,9\%), sendo que $66,4 \%$ estão na faixa etária entre 31 a $40(33,6 \%)$ e entre 41 a $50(32,8 \%)$ anos de idade. Quanto ao estado civil, os casados representam $45,4 \%$ e $60 \%$ possuem filhos. Dado importante considerando que as atividades educacionais presenciais foram suspensas e o trabalho remoto, no contexto da pandemia, ocorre quase que exclusivamente nas residências dos trabalhadores/as. Dinâmica que amalgama a vida laborativa com a privada, não sendo possível separar o espaço doméstico do espaço do labor. Esse processo torna-se mais expressivo quando a análise é feita pelo recorte de gênero devido às disparidades ainda presentes entre os papéis socialmente atribuídos a homens e mulheres. As análises de Bridi, Bezerra e Zanoni (2020) sobre trabalho remoto e gênero, afirmam que os aspectos negativos dessa modalidade de trabalho atingem ambos os sexos de forma distinta. Devido às desigualdades na divisão do trabalho doméstico e de cuidados, as mulheres são impelidas a assumirem jornadas super extensas de trabalho e a laborarem mais dias na semana, principalmente aquelas que possuem filhos.

\footnotetext{
4 A equipe da pesquisa foi composta por Fernanda Bohler, Fernanda Maia Landolfi, Kelen Aparecida da Silva Bernardo, Alexandre Pilan Zanoni, Mariana Bettega Braunert, Giovana Uehara, Zélia Freiberger e coordenada por Maria Aparecida Bridi.
} 
As configurações do trabalho remoto da categoria docente no contexto da pandemia covid-19| Kelen Aparecida da Silva Bernardo | Fernanda Landolfi Maia \& Maria Aparecida Bridi

No tocante a qualificação profissional dos respondentes da pesquisa, verifica-se que são trabalhadores com um grau elevado de qualificação, uma vez que os que possuem mestrado $(29,4 \%)$ e doutorado $(42,4 \%)$ representam a maioria. O coletivo é composto por 93,3\% que indicaram pertencerem somente a categoria docente, mas também se observa a coexistência de outras categorias como: professores e mentores $(0,4 \%)$, professores e pesquisadores $(1,5 \%)$, professores e redatores $(0,4 \%)$ e professores e técnicos de laboratório $(0,4 \%)$. Interessante notar que há participantes que exercem mais de uma função dentro da área educacional, o que demanda duplicidade de jornadas de trabalho, polivalência e multiplicidade de conhecimentos e habilidades desses profissionais (MAIA; BERNARDO, 2020b).

A partir de metodologias que articulam abordagens qualitativas e quantitativas, organizou-se o banco de dados referentes aos trabalhadores e trabalhadoras vinculados à educação, procedeu-se às análises das questões objetivas, demonstrando o perfil e a avaliação do grupo quanto às condições do trabalho docente remoto. Quanto às questões subjetivas, estas foram organizadas e categorizadas a partir de três eixos, como se pode visualizar no Quadro 1: intensificação, condições e organização do trabalho:

QUADRO 1 - EIXO DE ANÁLISE DO TRABALHO DOCENTE NA MODALIDADE ENSINO REMOTO EMERGENCIAL (ERE)

\begin{tabular}{|c|l|}
\hline Eixo & \multicolumn{1}{|c|}{ Descritivo de análise } \\
\hline Intensificação do trabalho & $\begin{array}{l}\text { Analisar o ritmo de trabalho, a alteração de } \\
\text { jornadas e as metas de produtivismo. }\end{array}$ \\
\hline Condições objetivas de trabalho & $\begin{array}{l}\text { Analisar as condições de trabalho dos } \\
\text { professores tais como, a infraestrutura, o } \\
\text { espaço físico, as plataformas de trabalho e os } \\
\text { equipamentos. }\end{array}$ \\
\hline Organização do trabalho & $\begin{array}{l}\text { Analisar como os professores realizam seu } \\
\text { trabalho, distribuem as atividades, as } \\
\text { gravações, a presença on-line e outros. }\end{array}$ \\
\hline
\end{tabular}

Fonte: As autoras (2020).

A escolha dos eixos de análise corresponde aos dados oriundos das informações obtidas do banco de dados do relatório técnico sobre "O 
As configurações do trabalho remoto da categoria docente no contexto da pandemia covid-19 |

Kelen Aparecida da Silva Bernardo | Fernanda Landolfi Maia \& Maria Aparecida Bridi

trabalho remoto no cenário da COVID-19" com o filtro para o setor educacional (MAIA; BERNARDO, 2020b). Ressalta-se, em especial, as questões abertas que possibilitaram uma análise mais adensada sobre a organização do trabalho docente na modalidade remota dos participantes da pesquisa.

O processo de compreensão e análise de um fenômeno demanda distanciamento e tempo para que se possa identificar suas diversas facetas, consonâncias e contradições. Refletir sobre as condições desse novo trabalho remoto, realizado no espaço doméstico no contexto da pandemia, exige certos cuidados e delimitadores, principalmente pelas especificidades que ele assumiu, se diferenciando do trabalho remoto, home office ou teletrabalho que já vinha sendo executado no Brasil, em diversos setores da economia, sejam públicos ou privados, embora não na dimensão de outros países desenvolvidos. Dada a urgência e a provisoriedade que permearam o processo de transição do trabalho presencial para o remoto como medida de enfrentamento da COVID-19, fez-se necessário estabelecer alguns marcadores para balizar as análises sobre as condições do trabalho docente na modalidade remota (BRIDI, 2020).

Adotamos como perspectiva teórica que teletrabalho e o home office não são sinônimos. No que se refere ao teletrabalho, pela perspectiva jurídica, a Lei $\mathrm{n}^{\circ}$ 13.467/2017 que versa sobre a Reforma Trabalhista, normatizou o teletrabalho por meio dos artigos 75-A ao 75-E, alterando a Consolidação da Lei Trabalhista (CLT) e distinguindo o trabalho realizado na instituição física ou remotamente. O artigo 75-B, define que: “considera-se teletrabalho a prestação de serviços preponderantemente fora das dependências do empregador, com utilização de tecnologias de informação e comunicação que, por sua natureza, não se constituam como trabalho externo" (BRASIL, 2017c). Nessa modalidade de teletrabalho o controle da jornada é dispensável, no entanto há a obrigatoriedade de registro em contrato de trabalho, assim como a previsão em contrato das despesas e provisões necessárias a realização das atividades laborais. Também é normatizado que não há horas extras quando inexiste o controle da jornada 
As configurações do trabalho remoto da categoria docente no contexto da pandemia covid-19 |

Kelen Aparecida da Silva Bernardo | Fernanda Landolfi Maia \& Maria Aparecida Bridi

de trabalho. Assim, as atividades externas que não possuem local fixo de trabalho não se enquadram como teletrabalho, a exemplo de vendedores, motoristas, entre outras.

Em relação ao trabalho remoto/home office, a organização pode ser híbrida, pois o uso da tecnologia de informação e comunicação não é uma regra, podendo ou não compor a dinâmica de trabalho. Dispensa registros em contrato individual de trabalho ou aditivo contratual e o regime de trabalho é flexibilizado, ocorrendo atividades remotas e, também, presenciais. Na legislação brasileira de 2011, os trabalhadores na modalidade teletrabalho possuem os mesmos direitos daqueles que executam suas atividades nas dependências da instituição. Já a reforma trabalhista de 2017, que regulamentou o teletrabalho, limitou-se a dizer tratar-se de um tipo de trabalho distante da empresa, que não se trata de trabalho externo e que o mesmo é realizado por meio das tecnologias de informação (MACHADO, BRIDI, 2020).

Segundo Machado e Bridi (2020), há diversos conflitos em razão das condições do teletrabalho, sendo alguns pontos elencados questionados na justiça como, por exemplo, a responsabilidade quanto a acidentes de trabalho ou doenças ocupacionais. Também é polêmica a questão do controle da jornada de trabalho na modalidade teletrabalho, pois quando a empregadora adota mecanismos de controle, as horas-extras são passiveis de comprovação e questionamentos. Verifica-se diferenças que influenciam nas condições e relações de trabalho nas duas modalidades, teletrabalho ou home office como, por exemplo, quanto ao controle da jornada de trabalho e a responsabilização quanto aos riscos ocupacionais.

Ainda, a questão conceitual vem sendo lapidada pelos autores que tratam da temática do trabalho remoto. Segundo Rosenfield e Alves (2011) a Organização Internacional do Trabalho (OIT) utiliza o conceito de teletrabalho sob a ótica de variáveis como: local/espaço de trabalho; horário/tempo de trabalho (trabalho integral ou parcial), tipo de contrato (assalariado ou independente) e conteúdo do trabalho. Para Antunes (2020), 
As configurações do trabalho remoto da categoria docente no contexto da pandemia covid-19 |

Kelen Aparecida da Silva Bernardo | Fernanda Landolfi Maia \& Maria Aparecida Bridi

essas modalidades configuram-se como uma potencialidade no contexto póspandemia, uma vez que vem sendo adotadas de maneira eminente.

No contexto da pandemia, devido à necessidade de distanciamento social, o reconhecimento de estado de calamidade pública, bem como a normatização da Medida Provisória 927/2020 que dispensou algumas formalidades para a adoção do trabalho fora das instalações físicas das instituições, o trabalho remoto ou home office, se constitui em uma das modalidades do teletrabalho. Considerando que é desse trabalho realizado no domicílio dos trabalhadores que envolve o uso intensivo de equipamentos informacionais (computadores, celulares, internet, webcam, etc.); e que a modalidade teletrabalho implica em acordo prévio entre as partes; e em razão do caráter emergencial provocado pela pandemia e não configurando como teletrabalho em seu sentido clássico, adotamos o conceito de trabalho remoto ou home office. O posicionamento teórico tem como base o entendimento de que a conjuntura delineada pela crise sanitária provocada pelo coronavírus imprime novas especificidades ao trabalho que, em situação não pandêmica é realizado presencialmente nas instituições educacionais.

Importante demarcar que as condições e relações de trabalho na modalidade remota assumem contornos e características distintas dependendo de alguns fatores importantes como o setor, se público ou privado e a modalidade de vínculo, se estatutário, celetista ou autônomo. São marcadores que precisam ser considerados ao analisar o trabalho remoto.

A exemplo disso, no âmbito federal, a Instrução Normativa $n^{\circ} 65$ de 30 de julho de 2020 estabelece orientações, critérios e procedimentos gerais para os órgãos e entidades da administração pública federal relativos à implementação de Programa de Gestão para a implantação do teletrabalho. São previstas a elaboração de plano de trabalho com previsão de "metas a serem alcançadas expressas em horas equivalentes"; a responsabilização do trabalhador com a estrutura necessária para a prática do teletrabalho como disposto no Art. 23. 
As configurações do trabalho remoto da categoria docente no contexto da pandemia covid-19|

Kelen Aparecida da Silva Bernardo | Fernanda Landolfi Maia \& Maria Aparecida Bridi

Art. 23. Quando estiver em teletrabalho, caberá ao participante providenciar as estruturas física e tecnológica necessárias, mediante a utilização de equipamentos e mobiliários adequados e ergonômicos, assumindo, inclusive, os custos referentes à conexão à internet, à energia elétrica e ao telefone, entre outras despesas decorrentes do exercício de suas atribuições (BRASIL, 2020a).

Para esses trabalhadores, acessar essa modalidade de trabalho também significa arcar com os custos da atividade laborativa. O trabalhador também é responsabilizado pela manutenção de infraestrutura relacionadas à segurança da informação. A transferência do ônus das atividades para os trabalhadores no trabalho de docentes vinculados ao setor público, já vinha ocorrendo em algumas situações, como analisado por Bernardo (2020). No caso do trabalho no setor privado, em muitos casos dependeu de decisões das instituições contratantes, em alguns casos de acordos com os sindicatos ou simplesmente de acordo com as recentes normativas de flexibilização do trabalho.

\section{O trabalho docente na modalidade remota}

O trabalho docente vem recebendo atenção por parte de pesquisadores como Apple e Kenneth (2003), Piton (2004), Frigotto, Ciavatta e Ramos (2005), Maronese (2009), Souza (2011), Nauroski (2014), entre outros, que buscaram em suas pesquisas compreender a experiência vivenciada por esses trabalhadores na cotidianidade do trabalho, são pesquisas que evidenciam os processos de regulamentação sobre patamares rebaixados - uma nova regulação menos protetiva - e de uma flexibilização negativa do trabalho docente. Considerando esse contexto, do avanço dessa agenda neoliberal sobre o oficio docente na dinâmica vivenciada antes da pandemia mundial, é urgente buscar compreender como se delineou o trabalho docente remoto forjado pelo distanciamento social no contexto da COVID-19.

O trabalho docente e suas possiveis formas de realização, caracterizado predominantemente pelas modalidades de ensino presencial e ensino à distância vem passando, no ano de 2020, por um grande desafio: o 
As configurações do trabalho remoto da categoria docente no contexto da pandemia covid-19 | Kelen Aparecida da Silva Bernardo | Fernanda Landolfi Maia \& Maria Aparecida Bridi

ensino remoto. Com o cenário da pandemia COVID-19 e a urgência pelo isolamento social a primeira tomada de decisão por parte da esfera governamental foi a suspensão das atividades educacionais de maneira presencial em todos os niveis de ensino, desde a educação infantil, séries iniciais, ensino fundamental, médio e ensino superior.

Num segundo momento, as portarias $n^{\circ} 343$ e n $^{\circ} 345$, de 17 e 19 de março deste ano, autorizam a realização do ensino remoto emergencial (ERE) para todas as instituições de educação superior integrantes do sistema federal de ensino que conforme estabelece o Decreto n. 9.235/2017 são: "as instituições federais de ensino superior - IFES; as IES criadas e mantidas pela iniciativa privada; e os órgãos federais de educação superior" (BRASIL, 2017a).

Destaca-se que o ensino remoto e suas especificidades assumido no contexto da pandemia não se trata de ensino à distância (EAD), pois essa modalidade pressupõe um tipo de contrato, uma estrutura (com templates, gravação em estúdio, materiais específicos, tutores, entre outros). Tampouco pode-se caracterizá-lo de ensino híbrido (parte presencial e parte à distância). Na compreensão de Behar (2020) o ERE é uma forma de ensino que presume o "distanciamento geográfico de professores e alunos e foi adotada de forma temporária nos diferentes niveis de ensino por instituições educacionais do mundo inteiro para que as atividades escolares não sejam interrompidas" (BEHAR, 2020, n/p). Dada a urgência do contexto de pandemia, o ensino presencial físico transitou para o remoto, sendo viabilizado pelas tecnologias de informação e comunicação (TICs) e de forma distinta da EAD:

No ERE, a aula ocorre num tempo síncrono (seguindo os princípios do ensino presencial), com videoaula, aula expositiva por sistema de webconferência, e as atividades seguem durante a semana no espaço de um ambiente virtual de aprendizagem (AVA) de forma assíncrona. A presença física do professor e do aluno no espaço da sala de aula presencial é 'substituída' por uma presença digital numa aula online, o que se chama de 'presença social'. Essa é a forma como se projeta a presença por meio da tecnologia (BEHAR, 2020, n/p). 
As configurações do trabalho remoto da categoria docente no contexto da pandemia covid-19 |

Kelen Aparecida da Silva Bernardo | Fernanda Landolfi Maia \& Maria Aparecida Bridi

Portanto, nessa modalidade de ensino, na perspectiva da autora supracitada, a interação e participação entre os docentes e os discentes é mais ativa e dinâmica, ocorrendo momentos de contatos em tempo real. Ainda para Moreira, Henriques e Barros (2020) a migração obrigatória de professores e estudantes para a realidade online, foi uma fase importante de transição:

\begin{abstract}
em que os professores se transformaram em youtubers gravando vídeo aulas e aprenderam a utilizar sistemas de videoconferência, como o Skype, o Google Hangout ou o Zoom e plataformas de aprendizagem, como o Moodle, o Microsoft Teams ou o Google Classroom (MOREIRA; HENRIQUES; BARROS, 2020, p. 352).
\end{abstract}

Com base nos apontamentos anteriores concordamos com a afirmação de Behar (2020) de que no contexto de pandemia, grande parte das instituições educacionais está ofertando o Ensino Remoto Emergencial. Embora haja na conjuntura nacional grandes conglomerados de grupos educacionais que atuam fortemente na modalidade EAD e que, portanto, para essa parcela não se perceba grandes impactos na aplicabilidade do Ensino Remoto Emergencial em função da infraestrutura já estabelecida, não é disto que se trata esta pesquisa. Mas sim de evidenciar que, com a interrupção abrupta do funcionamento presencial das instituições educacionais, não houve o necessário planejamento e nem processo de adaptação para a transição das atividades presenciais para a remota. Isto é o que revela a pesquisa sobre o trabalho remoto no contexto da pandemia, que realizamos, como já informada anteriormente. Esta pesquisa demonstrou que, no caso do trabalho docente que passou a ser realizado remotamente, a partir do domicílio, apresentam as condições gerais de um trabalho que se deu em caráter emergencial, transitório e sob condições, muitas vezes, improvisadas.

\title{
Modalidade contratual, condições de trabalho e avaliação da modalidade do trabalho remoto: análise dos resultados
}

Considerando, portanto, o caráter emergencial que o ensino remoto foi adotado e partindo do pressuposto de que o trabalho docente demanda 
As configurações do trabalho remoto da categoria docente no contexto da pandemia covid-19 |

Kelen Aparecida da Silva Bernardo | Fernanda Landolfi Maia \& Maria Aparecida Bridi

uma estrutura física, como espaço, mesas, cadeiras e tecnologias, indagouse sobre as condições ergonômicas em que os entrevistados da pesquisa realizavam suas atividades. Na avaliação dos respondentes, as condições de trabalho na modalidade remota, quanto à ergonomia, foram consideradas razoáveis por $53,8 \%$. Isto porque estes relataram que não dispõem de um espaço específico para realização do trabalho, mas apenas mesa e cadeira. Quanto às tecnologias e equipamentos necessários para o desempenho do trabalho remoto, 56,5\% consideram razoáveis suas condições, uma vez que dispunham de apenas de parte dos recursos de que necessitam para desempenhar seu trabalho, um computador e uma conexão de internet.

Em relação as modalidades de contratos dos respondentes de pesquisa, tanto no setor público quanto privado, identificamos uma diversidade de modalidades de contratos de trabalho, compreendendo tanto as formas protegidas de trabalho como os estatuários e celetistas, quanto formas flexiveis, caso dos trabalhadores autônomos, MEI, estagiários e contratos por tempo determinados, que são modalidades de contratos precárias.

Entre os dados da pesquisa vale ressaltar que o setor público configura como o principal empregador dos docentes, representando 67,6\% dos que responderam à pesquisa. Entre os professores do setor público, a modalidade de vínculo predominante é a estatutária com 75\%. Com regime próprio, os estatutários possuem direitos a estabilidade e acessam um conjunto de direitos e garantias previstas legalmente para a categoria docente. Outro vínculo identificado foi o contrato de trabalho temporário, representando $16 \%$ dos respondentes. O contrato temporário na administração pública difere do realizado na esfera privada e foi inicialmente concebido pelo Estado para atender demandas urgentes até que se providencie a contratação via concurso público. No entanto, essa forma de contrato vem aumentado significativamente na administração pública nas diversas esferas administrativas. Essa forma de contratação, como analisa Bernardo (2020), assume características específicas, configurando como trabalhadores com vínculos que, apesar de serem formais, ainda sim, são 
As configurações do trabalho remoto da categoria docente no contexto da pandemia covid-19 | Kelen Aparecida da Silva Bernardo | Fernanda Landolfi Maia \& Maria Aparecida Bridi

instáveis, inseguros e com reduzidos direitos, pois não acessam todos os direitos dos estatutários e nem os direitos do trabalho dos celetistas. Os com vínculos CLT representam 5\% dos participantes. Estes possuem uma estabilidade relativa, pois não integram o regime estatutário, no entanto "só podem ser demitidos mediante processo administrativo que comprove justa causa" (BRIDI; BRAUNERT; BERNARDO, 2019, p. 106).

Em relação às modalidades de vínculos de trabalho no setor privado, que representa $32,4 \%$ dos entrevistados da pesquisa, o vínculo predominante é celetista. Ou seja, $87,1 \%$ entre os entrevistados do setor privado têm contrato CLT. Os celetistas possuem direitos como $13^{\circ}$ salário, férias remuneradas, FGTS e seguro-desemprego, vale transporte, aviso prévio, bem como licença maternidade, entre outros benefícios. Já os temporários, aqueles com contrato por tempo determinado, que somam 5,9\% dos entrevistados ficam fora de certos direitos garantidos apenas aos contratados por tempo indeterminado. No setor privado, essa forma de contratação configura-se como vínculo empregatício precário e, com a aprovação da Reforma Trabalhista - Lei no 13.429 (BRASIL, 2017b), o tempo máximo de duração de contrato de trabalho temporário foi estendido de 90 (noventa) dias para 180 (cento e oitenta) dias. Seguindo com a análise, 4,7\% dos que responderam à pesquisa são autônomos. As modalidades de estágio e micro empreendedor individual aparecem com $1,2 \%$, respectivamente.

A análise dos dados referentes as modalidades de contratação revelaram que em ambos os setores, público e privado, estão presentes formas flexiveis de trabalho. Chama a atenção o fato de que no setor público, o índice de contratos temporários é maior quando comparado ao privado. Para ilustrar, como segue o quadro.

QUADRO 2 - SETOR PÚBLICO E PRIVADO: FORMAS FLEXÍVEIS DE CONTRATAÇÃO DOS RESPONDENTES DA PESQUISA

\begin{tabular}{|c|c|c|c|}
\hline Setor público & Respondentes & Setor privado & Respondentes \\
\hline $\begin{array}{c}\text { Contrato por tempo } \\
\text { determinado, CLT, Cargo em } \\
\text { Comissão, Bolsista, Autônomo }\end{array}$ & $23 \%$ & $\begin{array}{c}\text { MEl, Estagiário, Autônomo, } \\
\text { Contrato por Tempo } \\
\text { Determinado }\end{array}$ & $13 \%$ \\
\hline
\end{tabular}

Fonte: Elaborado pelas autoras, 2020. 
As configurações do trabalho remoto da categoria docente no contexto da pandemia covid-19|

Kelen Aparecida da Silva Bernardo | Fernanda Landolfi Maia \& Maria Aparecida Bridi

Há diferentes modalidades contratuais em cada setor, se público ou privado, como também se federal, estadual e ou municipal. Contudo, não exploramos essas diferenças nesta pesquisa. A modalidade de vínculo é importante para compreensão das relações de trabalho que esses docentes estão submetidos, influenciando também nas condições de trabalho, pois cada esfera possui dinâmicas próprias de organização e regulação da atividade docente. Na pandemia, essa questão tornou-se ainda mais evidente com a adoção de ações reguladas pela Medida Provisória ${ }^{\circ}$ 936, convertida na Lei 14.120/2020, que instituiu o Programa Emergencial de Manutenção do Emprego. Entre as medidas autorizadas, válidas somente para o setor privado, estão a redução proporcional de jornada de trabalho e de salário e a suspensão temporária do contrato de trabalho, implicando em uma piora nas condições de trabalho, uma vez que os rendimentos passam a ser insuficientes para a sobrevivência dos trabalhadores e trabalhadoras atingidos por essas medidas.

\section{Condições objetivas de trabalho: percepção dos entrevistados}

O trabalho desenvolvido pelos professores na modalidade de ensino remoto emergencial exigiu adequações com relação a organização do próprio trabalho a começar pelos espaços que estão sendo utilizados para a efetivação das aulas, sejam síncronas ou assíncronas. A seguir, o Gráfico 1 apresenta as percepções dos professores a respeito da ergonomia dos espaços de trabalho no âmbito doméstico (home office). 
As configurações do trabalho remoto da categoria docente no contexto da pandemia covid-19| Kelen Aparecida da Silva Bernardo | Fernanda Landolfi Maia \& Maria Aparecida Bridi
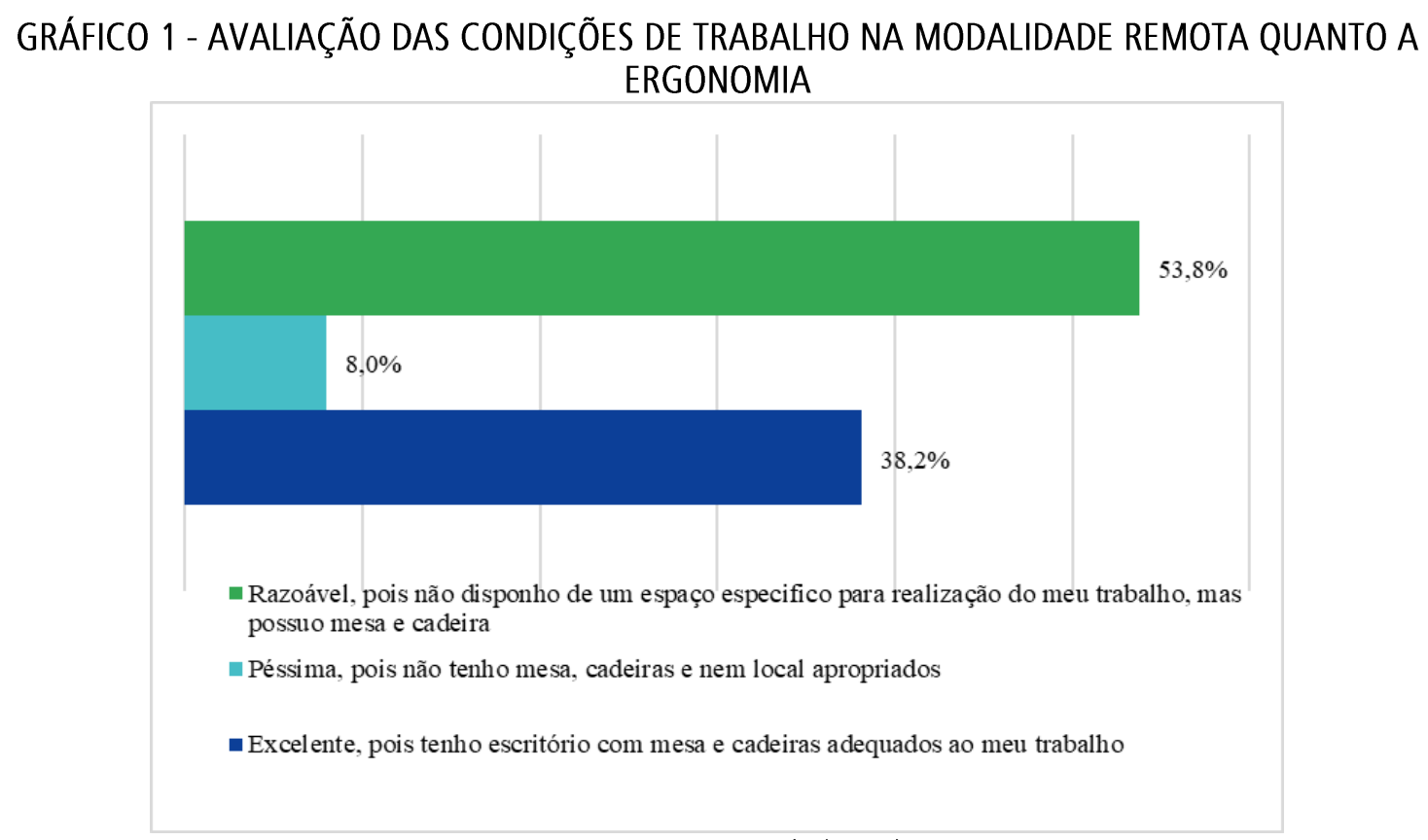

Fonte: Maia e Bernardo (2020).

Observa-se, assim, que $38,2 \%$ dos respondentes apontam ser excelente a ergonomia para execução do trabalho, pois possuem escritório com mesa e cadeiras adequados, 53,8\% consideram razoável pois não dispõem de um espaço específico, mas possuem mesa e cadeira e 8,0\% considera péssimo o ambiente para execução das atividades laborais, pois não têm mesas, cadeiras ou locais apropriados para o trabalho remoto. Além do aspecto de ergonomia os respondentes apontam as condições dos equipamentos e tecnologias necessários para a realização das atividades.

Outro elemento que compõe as condições objetivas do trabalho dos entrevistados são as exigências e aplicação de metas de produtividade acadêmica. Com relação aos critérios e metas de produtividade, $50 \%$ dos docentes apontaram que há critérios estabelecidos. Já para os outros 50\% não há exigência nesse sentido. Entretanto, quando questionados a respeito de possiveis alterações das metas no período da pandemia, os respondentes puderam indicar uma das quatro opções pré-estabelecidas: "aumentou a meta de produtividade", "diminuiu a meta de produtividade", "não houve alteração quanto a meta" e "não se aplica ao meu trabalho". Os percentuais podem ser observados no Gráfico a seguir: 
As configurações do trabalho remoto da categoria docente no contexto da pandemia covid-19| Kelen Aparecida da Silva Bernardo | Fernanda Landolfi Maia \& Maria Aparecida Bridi

GRÁFICO 2 - ALTERAÇÕES DOS CRITÉRIOS DE META DE PRODUTIVIDADE

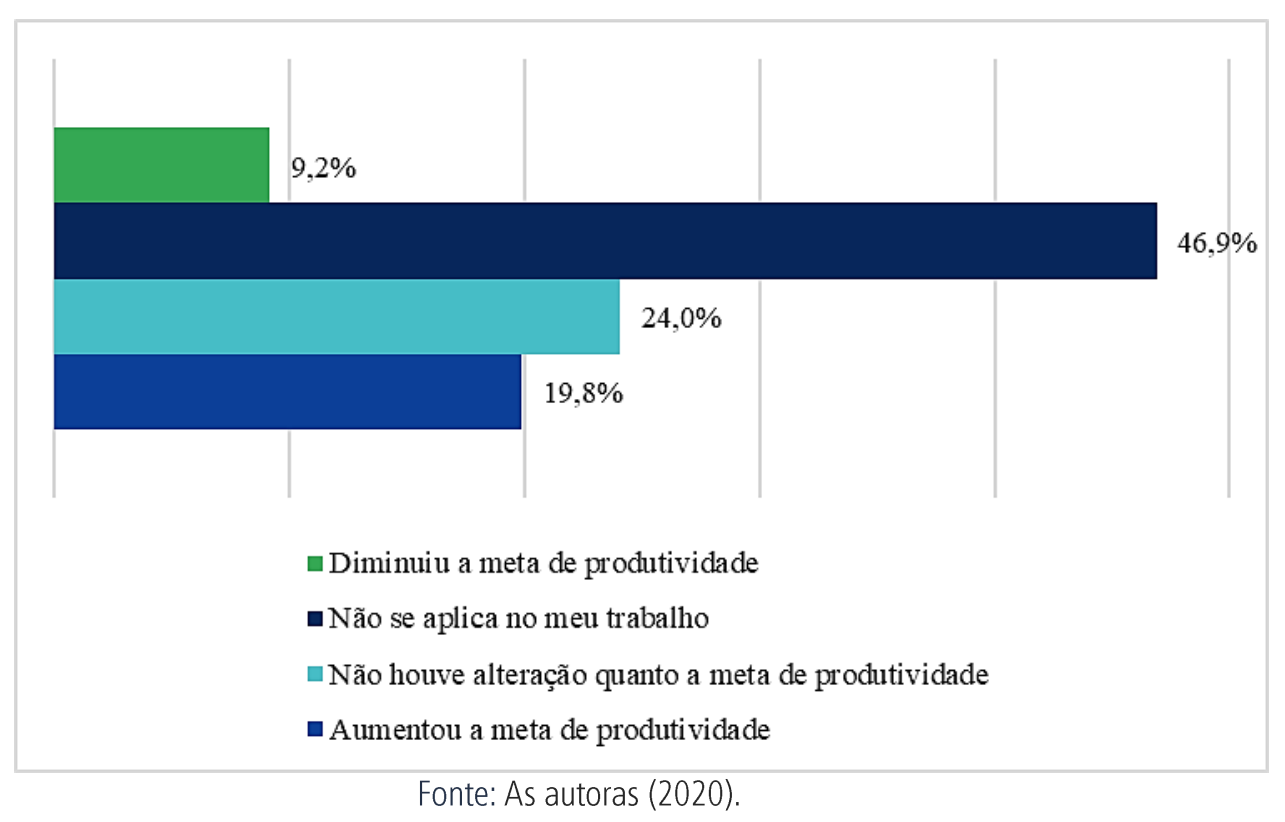

Entre as respostas observa-se que 46,9\% informaram que a questão de metas não se aplica ao trabalho que desenvolve como docente. Dentre aqueles que apontaram que há critérios estabelecidos, 24,0\% afirmaram que não houve alterações com relação às metas de produtividade no trânsito do trabalho presencial para o remoto e 9,2\% perceberam que ocorreu diminuição das metas de produtividade no trabalho remoto quando comparado ao trabalho presencial. Porém, 19,8\% dos trabalhadores tiveram suas metas ampliadas durante o período de trabalho remoto. Avaliamos que esta percepção pode estar relacionada a quantidade de novas tarefas que tiveram que realizar, tais como gravar aula, postar, propor atividades assíncronas, entre outras.

Outro elemento fundamental para a compreensão das condições objetivas do trabalho docente é o comparativo entre a média de horas trabalhadas antes e durante a pandemia, como pode-se visualizar no gráfico seguinte. 
As configurações do trabalho remoto da categoria docente no contexto da pandemia covid-19| Kelen Aparecida da Silva Bernardo | Fernanda Landolfi Maia \& Maria Aparecida Bridi

\section{GRÁFICO 3 - COMPARATIVO DA MÉDIA DE HORAS DIÁRIAS TRABALHADAS ANTES E DURANTE A PANDEMIA}

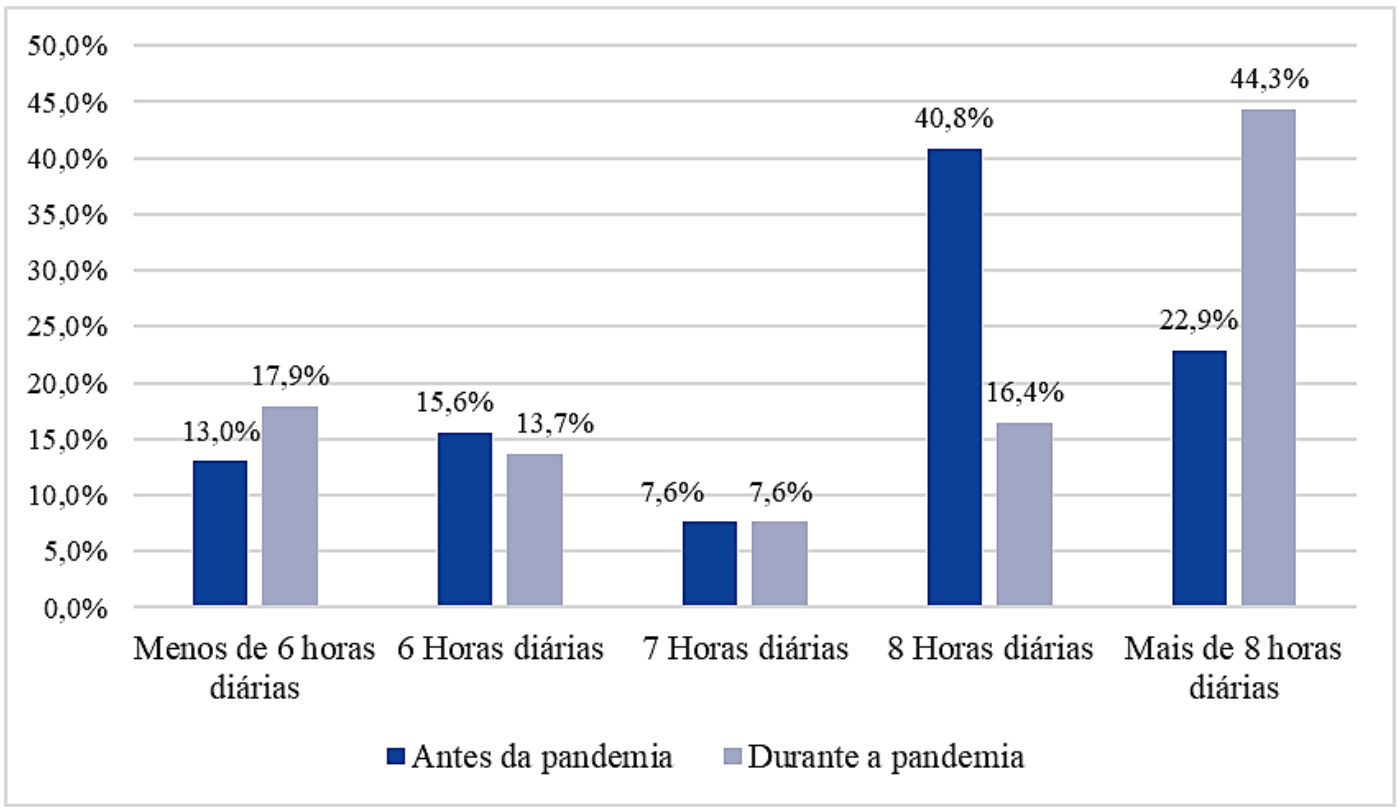

Fonte: As autoras (2020).

Entre os dados do gráfico acima dá-se relevo aqueles que demonstram a ocorrência de uma diminuição de 40,8\% para $16,4 \%$ dos que trabalhavam 8 horas diárias na comparação antes e durante a pandemia. Também é possivel observar um aumento no número de pessoas com mais de 8 horas de trabalho diárias, passando de 22,9\% para 44,3\% daqueles que trabalham mais de 8 horas diárias durante a pandemia. Conforme os dados analisados por Bridi, Uehara e Zanoni (2020), a modalidade do trabalho remoto impactou de forma desigual homens e mulheres. Embora não tenham feito o recorte específico para o caso dos docentes, os autores identificaram que na pandemia o trabalho foi intensificado devido à ampliação das jornadas de trabalho e de dias trabalhados. Sendo que a intensificação também se relaciona com ter ou não filhos. Concluíram que para as mulheres com dois filhos:

[...] há tendência crescente de trabalhar mais dias por semana, e decrescente nas mulheres sem filhos. O mesmo não se observa em relação aos homens com filhos. Entre as mulheres que trabalham sete dias por semana, as que possuem dois filhos representam a maioria [...]. Devido ao acúmulo de tarefas domésticas e de cuidado dos filhos, as mulheres são mais interrompidas durante suas jornadas de trabalho e necessitam de mais dias para realizarem as 
As configurações do trabalho remoto da categoria docente no contexto da pandemia covid-19 | Kelen Aparecida da Silva Bernardo | Fernanda Landolfi Maia \& Maria Aparecida Bridi

mesmas atividades que os homens (BRIDI; BEZERRA; ZANONI, $2020, \mathrm{~s} / \mathrm{p})$.

Além da comparação da média de horas diárias trabalhadas, a pesquisa buscou estabelecer um comparativo entre o número de dias da semana dedicado ao labor, antes da pandemia presencialmente e durante a pandemia remotamente.

GRÁFICO 4 - COMPARATIVO DE DIAS TRABALHADAS SEMANALMENTE ANTES E DURANTE A PANDEMIA

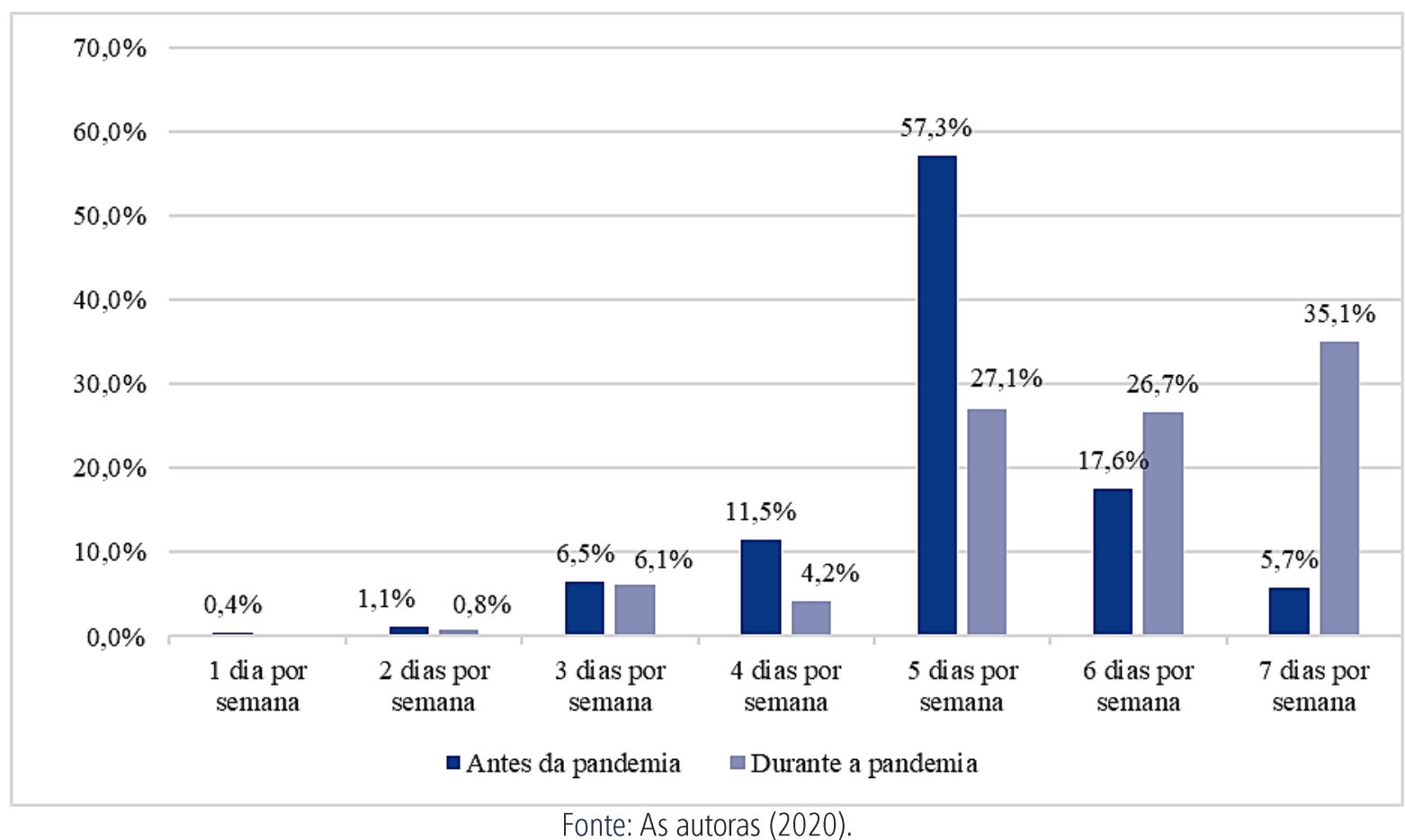

Quando estabelecemos uma análise comparativa nos dias da semana dedicados ao trabalho antes e durante a pandemia verificamos o seguinte delineamento: antes da pandemia, os que trabalhavam 5 dias na semana eram 57,3\%, 6 dias eram 17,6\% e 7 dias apenas 5,7\%; durante a pandemia, na modalidade remota, ocorrem flutuações, pois o percentual dos que trabalham 5 dias durante a semana caiu para $27,1 \%$, enquanto aumentaram os que trabalham 6 e 7 dias, passando para 26,7\% e 35,1\% respectivamente. Na comparação dos dados, verifica-se dois pontos de mudanças mais expressivas para os respondentes da pesquisa: uma significativa redução dos que trabalhavam 5 dias na semana e um 
As configurações do trabalho remoto da categoria docente no contexto da pandemia covid-19 |

Kelen Aparecida da Silva Bernardo | Fernanda Landolfi Maia \& Maria Aparecida Bridi

importante aumento dos que trabalham 7 dias, ou seja, todos os dias da semana.

Quando perguntados sobre o ritmo de trabalho, para 59,9\% dos respondentes da pesquisa, o ritmo passou a ser mais acelerado no trabalho remoto, enquanto para 30,2\% apontam que passaram a trabalhar num ritmo mais lento e 9,9\% dos respondentes não percebem mudanças no ritmo de trabalho. Para Dal Rosso (2008) o ritmo e a velocidade em que o trabalhador desenvolve suas atividades pode implicar num quadro de intensificação do trabalho. A partir dos dados da pesquisa, é possível identificar que esse coletivo de docentes passou a trabalhar mais dias durante a semana.

Os dados apontam que para uma parcela dos docentes houve um processo de intensificação com relação às horas diárias e dias trabalhados. Para Dal Rosso (2008, p. 46) "intensificar é exigir mais trabalhos e resultados superiores no mesmo espaço de tempo". No caso dos docentes, os depoimentos revelam aumento de jornada de trabalho, como também da carga de labor, em razão de terem que, concomitantemente a aprenderem desde a usar plataformas diversas, até a gravar aulas, disponibilizar materiais aos estudantes, elaborar e corrigir mais tarefas, entre outras atividades que representaram mais trabalho. Sendo assim, Maia (2014, p. 146) aponta que "o processo de intensificação não se dá de maneira isolada e, desta forma, entendemos que outro elemento é propulsor das transformações e reorganização do trabalho e implica nas suas configurações, que é a relação do trabalho com o seu tempo de execução".

Com base na pesquisa, consideramos que ao serem impelidos a desenvolveram as atividades docentes de forma remota, um percentual expressivo desses trabalhadores passou a ter jornadas de trabalho mais extensas com mais horas diárias, e mais dias da semana, e intensas, como um ritmo mais acelerado. As especificidades da natureza do trabalho docente, dado o seu caráter intelectual e imaterial, torna difícil mensurar o quanto de tempo marcado pelo relógio é necessário para cada atividade, como apontam as reflexões tecidas por Bernardo (2020). No contexto da pandemia da COVID-19 com a adoção do ensino emergencial remoto, o 
As configurações do trabalho remoto da categoria docente no contexto da pandemia covid-19| Kelen Aparecida da Silva Bernardo | Fernanda Landolfi Maia \& Maria Aparecida Bridi

delineamento do tempo de trabalho necessário para a elaboração, edição e diagramação das múltiplas atividades torna-se ainda mais complexo, pois a dinâmica de trabalho e sua produtividade são vinculados proporcionalmente ao grau de habilidades e familiaridade com as ferramentas e plataformas digitais.

$\mathrm{Na}$ avaliação dos docentes, o trabalho remoto apresenta complexidades, uma vez que $71,8 \%$ dos respondentes indicaram que encontram dificuldades para desenvolver suas atividades de formar remota. Para 28,2\%, as atividades são realizadas sem dificuldades. A pesquisa levantou quais os aspectos que dificultam o trabalho remoto a fim de compreender de que maneira os professores identificam as questões da organização das atividades laborais que tornam complexo o ensino na modalidade remota. As respostas foram compiladas e apresentadas no Gráfico 5.

GRÁFICO 5 - ASPECTOS DIFICULTADORES NO TRABALHO REMOTO

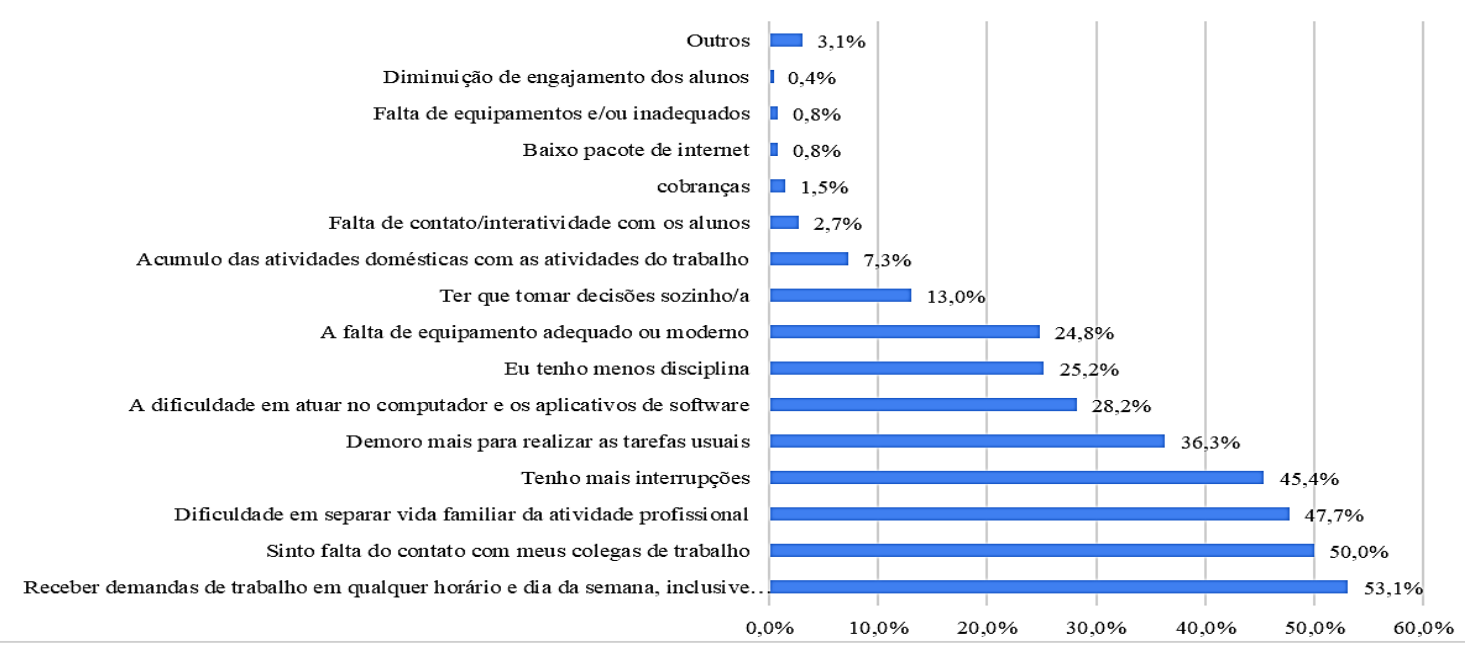

Fonte: As autoras (2020).

Com o objetivo de identificar as dificuldades, esta questão permitiu que o respondente marcasse os aspectos mais relevantes a partir de sua percepção. Na avaliação dos docentes, os aspectos que dificultam a realização do trabalho remoto são múltiplos e se inter-relacionam. O fato de "receber demandas de trabalho em qualquer horário e dia da semana, 
As configurações do trabalho remoto da categoria docente no contexto da pandemia covid-19 |

Kelen Aparecida da Silva Bernardo | Fernanda Landolfi Maia \& Maria Aparecida Bridi

inclusive fins de semana e feriados" aparece com maior percentual de citações, com 53,1\%, constituindo um aspecto de maior dificuldade. Nas análises de Maia e Bernardo (2020, p. 20) isso evidencia que "uma parcela expressiva dos respondentes trabalha em dias e horários que excedem suas jornadas", borrando as fronteiras entre tempo de trabalho e de não trabalho.

A falta de contato com os colegas de trabalho, consequência do isolamento social, também é citado como dificultador do trabalho remoto, aparecendo na avaliação de 50\% dos docentes. A dificuldade em separar a vida familiar da vida laborativa é um aspecto negativo para $47,7 \%$ dos participantes. $O$ fato de o trabalho remoto, no contexto da pandemia ser realizado principalmente no ambiente doméstico, os marcadores que separam a vida privada e a produtiva tornam-se fluídos e praticamente invisíveis. Consequentemente a questão de maior interrupção no processo de trabalho também é expressiva, sendo citada por $45,4 \%$, conectado com a produtividade, pois $36,3 \%$ avaliaram que demoram mais tempo para realizar as tarefas usuais. Outras questões relevantes referem-se "a dificuldade em atuar no computador e os aplicativos de software" indicados por $28,2 \%$ dos docentes, o que representa que o trabalho remoto passou a exigir dos docentes novos conhecimentos de plataformas e softwares para executar o trabalho, como demonstra o relato a seguir:

[...] obrigação de aprendermos por nós mesmos como funcionam as ferramentas do google classroom, o tempo excessivo em frente ao computador para conseguirmos resolver um problema simples, a dificuldade de organizar mentalmente o que diz respeito especificamente ao pedagógico [...] (DEPOIMENTO n. 100, 2020).

Ao analisar os principais fatores que dificultam o trabalho docente na modalidade remota, identifica-se conexões e relações que os influenciam mutuamente, constituindo-se consequência e efeito um do outro, como por exemplo a questão da dificuldade em separar vida familiar da laborativa pode ter como resultado maiores interrupções que, por sua vez, prejudicam a concentração e a produtividade demandando mais tempo para as atividades usuais e assim sucessivamente. 
As configurações do trabalho remoto da categoria docente no contexto da pandemia covid-19 | Kelen Aparecida da Silva Bernardo | Fernanda Landolfi Maia \& Maria Aparecida Bridi

Os aspectos que dificultam o trabalho docente na modalidade remota evidenciados na avaliação dos participantes apresentam um cenário de jornadas excessivas, dos usos dos tempos de trabalho de maneira intermitente, sem fronteiras entre espaços de trabalho e de não trabalho, assim como tempo de trabalho e de não trabalho invisiveis, como se houvesse uma personificação do homem-máquina full time. A respeito disso, Dal Rosso (2008, p. 40) analisa que

[...] a dimensão intelectual da intensidade não significa uma contribuição apenas ao trabalho do pesquisador, do professor, do intelectual e de todos aqueles que trabalham com atividades centralmente mentais [...], mas a todo componente mental e intelectual que passa a ser exigido cada vez mais pelo trabalho contemporâneo. Da mesma forma, invocar o componente emocional do trabalho [...] implica permitir uma nova janela para examinar todo o tipo de envolvimento emocional com o trabalho e novos desgastes emocionais exigidos pelos novos tipos de atividades aos trabalhadores de qualquer esfera.

Outra questão tratada na pesquisa refere-se à flexibilidade. As mutações no âmbito do trabalho pressionam os trabalhadores a serem mais flexíveis sendo que discurso da flexibilidade, sobre a retórica da modernização das relações e condições de trabalho, capitaneia a subjetividade dos trabalhadores. Sennett (2010) destaca que o termo flexibilidade é uma associação com a habilidade dos movimentos das árvores as quais se dobram em situações de ventos fortes, mas sempre voltam à posição inicial. A partir dessa perspectiva, Bernardo (2020) analisa que no âmbito do trabalho a flexibilidade é vinculada à exigência de que o trabalhador possua a capacidade de se dobrar ante as mudanças constantes que o mercado de trabalho impõe, mas que também tenha a habilidade de se restabelecer e adaptar-se.

No que tange ao trabalho remoto, a questão da flexibilidade é marcadamente presente, sendo apontado como fator positivo, como pode-se observar no Gráfico 6. 
As configurações do trabalho remoto da categoria docente no contexto da pandemia covid-19|

Kelen Aparecida da Silva Bernardo | Fernanda Landolfi Maia \& Maria Aparecida Bridi

GRÁFICO 6 - ASPECTOS FACILITADORES NO TRABALHO REMOTO

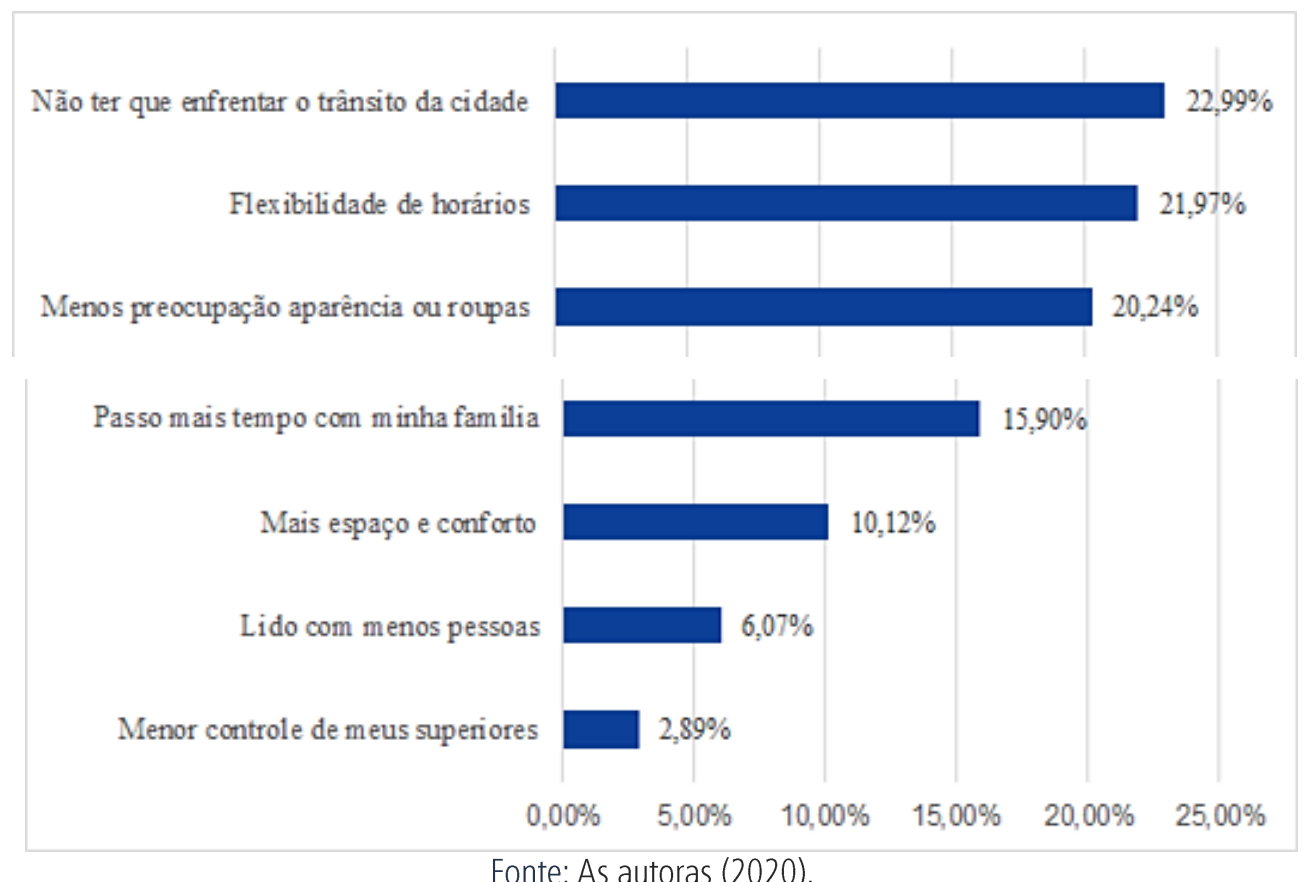

Fonte: As autoras (2020).

Na percepção dos docentes, o fato de não ter que enfrentar o trânsito das cidades é entendido como positivo para $22,9 \%$ dos respondentes. A flexibilidade de horários aparece para $21,9 \%$ dos respondentes, dicotomicamente o fato de não ter uma jornada de trabalho rígida, com delimitações de início e término, pode implicar em menor controle do tempo de trabalho ao passo que também possibilita jornadas mais longas. Outro fator apontado como positivo para $20,2 \%$ dos docentes é o fato de não ter que se preocupar com a aparência pessoal. Aspectos voltados a maior tempo de convivência familiar também são apontados como positivos por $15,9 \%$ dos docentes.

Ao refletir sobre a avaliação do trabalho remoto para o coletivo de docentes participantes da pesquisa, identificamos aspectos facilitadores, mas também outros que dificultam a prática docente, evidenciando o caráter antagônico e contraditório que o trabalho remoto no contexto da pandemia da COVID-19 assumiu. Se por um lado há processos de aumento da extensão e da intensidade do tempo de trabalho, por outro, o tempo economizado com o trânsito e a flexibilidade de horários facilitam o trabalho nessa modalidade. 
As configurações do trabalho remoto da categoria docente no contexto da pandemia covid-19| Kelen Aparecida da Silva Bernardo | Fernanda Landolfi Maia \& Maria Aparecida Bridi

Os dados empíricos corroboram com as análises realizadas por Antunes (2020) sobre as contradições do trabalho remoto. Segundo o autor supracitado, emergem como pontos positivos a ausência de deslocamentos, flexibilidade de horários e melhor qualidade na alimentação. Dicotomicamente, os pontos negativos versam sobre a individualização do trabalho, desustruturação das relações solidárias e coletivas, que por sua vez impactam no afastamento das experiências sindicais, fragilizando as resistências aos desmontes dos direitos vinculados ao trabalho (ANTUNES, 2020).

Para além do aspecto paradoxal, é necessário frisar que a adoção do trabalho remoto possibilitou a continuidade de parte das atividades acadêmicas, assim como possibilitou que um contingente significativo de trabalhadores continuasse a laborar com menor perigo de contágio da COVID-19. Por outro lado, os contornos assumidos do trabalho docentes na modalidade remota no contexto de isolamento social, levam a uma avaliação negativa da qualidade do trabalho realizado, uma vez que na percepção de $79,4 \%$ do conjunto dos professores que responderam à pesquisa consideraram que a qualidade do trabalho é melhor quando é realizado presencialmente.

\title{
Organização do trabalho
}

Com relação a organização do trabalho na modalidade remota, não há uma padronização coletiva nem individual, pois cada instituição adotou o trabalho remoto buscando atender suas especificidades, cabendo ao trabalhador, na sua individualidade, estabelecer a maneira de organizar a sua rotina. Para Maia, Muller e Bernardo (2020, p. 122):

\begin{abstract}
A análise sobre o trabalho remoto permite um duplo olhar: por um lado percebe-se a existência da individualidade no que tange a execução do trabalho, seguida da percepção de uma certa autonomia em função das atividades serem desenvolvidas de maneira solitária e sob o controle do trabalhador.
\end{abstract}

Neste cenário complexo de uma falsa autonomia, é responsabilidade do trabalhador o controle de sua rotina, bem como a organização do 
As configurações do trabalho remoto da categoria docente no contexto da pandemia covid-19 | Kelen Aparecida da Silva Bernardo | Fernanda Landolfi Maia \& Maria Aparecida Bridi

trabalho, entretanto há um controle na obrigatoriedade dos usos das métricas das plataformas adotadas pelas instituições. Observa-se na fala dos entrevistados esta questão "Ressalto o aspecto de ter mais formas de controle no trabalho remoto e a cobrança por parte da equipe gestora é bem maior, inclusive com exigência de realização de muitas atividades com interrupções até nos finais de semana" (DEPOIMENTO n. 94, 2020). De acordo com Rosenfield e Alves (2011), a autonomia no trabalho pode representar tanto uma autodeterminação e responsabilidade com as quais os trabalhadores conduzem suas rotinas, quanto as prioridades e métodos para a execução das atividades.

O questionário apresentou uma questão dissertativa em que os respondentes puderam apontar suas percepções sobre o trabalho remoto, assim como pontos positivos e negativos desta modalidade de atuação, dentro do cenário da pandemia da COVID-19. Entre as argumentações apresentadas, identificou-se a polivalência no que se refere ao exercício de diferentes atividades concomitantes, como se pode observar na seguinte fala: "Acúmulo de funções. Os professores, além de docentes passaram a ser também conteudistas, tutores, mentores e agentes comerciais" (DEPOIMENTO n. 216, 2020). Soma-se a demanda da polivalência com a ausência de estrutura física adequada, como relata outro docente: "A vida de professor já é dificil, remotamente acumulamos ainda mais atividades, como programador e preparação obrigatória de materiais pedagógicos para suprir a ausência do contato. Além disso tenho 2 filhos pequenos, tenho gravado aulas do carro, preparado materiais de madrugada" (DEPOIMENTO n. 166, 2020).

Paradoxalmente, identificamos aspectos positivos e negativos desta modalidade em um mesmo relato:

Particularmente prefiro, por ter mais autonomia, flexibilidade, não precisar me deslocar e socialmente não ter que lidar com tantas pessoas no cotidiano. Por outro lado, todo dia é um desafio, as demandas são imediatas e trabalho mais horas. Fico mais preocupada com todo o processo de uma linha produtiva, pois a educação virou um serviço, uma mercadoria (DEPOIMENTO, 2020, n. 213). 
As configurações do trabalho remoto da categoria docente no contexto da pandemia covid-19| Kelen Aparecida da Silva Bernardo | Fernanda Landolfi Maia \& Maria Aparecida Bridi

Observa-se que tanto os aspectos positivos quanto os negativos apontados a partir das percepções dos docentes, têm relação direta com a infraestrutura para a aplicabilidade das atividades, bem como o perfil do docente (se possui filhos, se possui escritório equipado em casa, outros). No que tange aos aspectos negativos percebe-se reincidência nas respostas de elementos como distanciamento social, intensificação do trabalho, excesso de interrupções e as dificuldades com relação a adaptabilidade, como se pode observar nas falas abaixo relacionadas no Quadro 3.

QUADRO 3 - PERCEPÇÕES DO TRABALHO NA MODALIDADE DE ENSINO REMOTO EMERGENCIAL

\begin{tabular}{|c|l|}
\hline Distanciamento social & $\begin{array}{l}\text { "O distanciamento social dos colegas e alunos é ruim, causa sensação de } \\
\text { não pertencimento à instituição" (Depoimento n. 118, 2020). }\end{array}$ \\
\hline $\begin{array}{c}\text { Intensificação do } \\
\text { trabalho }\end{array}$ & $\begin{array}{l}\text { "Houve a imposição de uma carga excessiva de trabalho com cobrança } \\
\text { curta de prazos de modo irregular, não distribuída a todos igualmente" } \\
\text { (Depoimento n. 219, 2020). }\end{array}$ \\
\hline \multirow{3}{*}{ Interrupções } & $\begin{array}{l}\text { "Não consigo realizar de forma integral meu trabalho. Há muitas } \\
\text { interrupções. Não há retorno satisfatório dos alunos. Não há tecnologia } \\
\text { suficiente. Teve redução salarial. Muito desrespeito à autonomia didático } \\
\text { pedagógica" (Depoimento n. 245, 2020). }\end{array}$ \\
\hline Adaptabilidade & $\begin{array}{l}\text { "De minha parte, todas as dificuldades são relevantes e passíveis de } \\
\text { adaptação/superação. 0 problema mais expressivo do trabalho remoto } \\
\text { reflete sobre o público-alvo (os alunos), pois a maioria não apresenta as } \\
\text { condições materiais para a realização dessas atividades à distância } \\
\text { (Depoimento n. 256, 2020). }\end{array}$ \\
\hline
\end{tabular}

Fonte: As autoras (2020).

Para os professores, o isolamento social tornou-se o nó górdio das relações que permeiam o ambiente educacional, tanto em relação às trocas com os colegas de área, quanto nas aulas, seja na modalidade síncrona ou assíncrona, pois trata-se de um contexto de individualização extrema, onde cada um está atrás de sua "máquina" exaurido com suas inúmeras atividades. Outra questão são as jornadas excessivas em função da quantidade de trabalho existente neste período e sobretudo, tendo como pano de fundo prazos curtos e imediatos da realização destas atividades. 
As configurações do trabalho remoto da categoria docente no contexto da pandemia covid-19 |

Kelen Aparecida da Silva Bernardo | Fernanda Landolfi Maia \& Maria Aparecida Bridi

A interrupção e a dificuldade de adaptabilidade também se somam ao cenário de exercício da docência, na modalidade remota. Como informaram os respondentes da pesquisa o trabalho realizado em ambiente domiciliar conta com inúmeras interrupções (filhos, demandas da casa). Assim, a adaptabilidade torna-se complexa pois, dentro desse cenário doméstico, de maneira isolada, muitos tiveram que compreender aspectos tecnológicos dos usos das ferramentas digitais para efetivar o trabalho, fazer aprendendo ao mesmo tempo.

\section{Considerações finais}

A pandemia da COVID-19, como mostrou a pesquisa "Trabalho remoto/home-office no contexto da pandemia COVID-19", afetou a toda a classe trabalhadora (BRIDI; BOHLER; ZANONI, 2020) de todos os setores econômicos e vínculos empregatícios. Entretanto, algumas categorias e grupos de trabalhadores, dentre os quais os docentes, foram mais impactadas. Enquanto houve demissão de grande número de docentes vinculados às instituições privadas, por exemplo, os que se mantiveram no trabalho remoto e não perderam o emprego, vivenciaram processos de um trabalho intensificado com inúmeras tarefas que se somaram aquelas existentes anteriormente à pandemia. Antecede à pandemia a categoria docente ter que "levar trabalho para casa", visto que uma grande parcela dos professores realiza parte do trabalho fora da sala de aula, seja na preparação, correção, etc. Entretanto, no cenário da pandemia, e tendo que realizar o trabalho de forma remota, com o uso de computadores, suas tarefas foram multiplicadas, pois além de preparar, tinham que gravar algumas vezes em mais de uma modalidade (vídeo, podcast) -, postar na plataforma eleita, preparar atividades assincronas, corrigir as atividades, devolvê-las, dentre outras. O aprendizado de uso de diferentes plataformas digitais também pode ter contribuído para um trabalho intensificado. Entretanto, o que foi comum, dos depoimentos em geral, foram às demandas a qualquer tempo e pelos diversos meios, seja por e-mail, por aplicativos de 
As configurações do trabalho remoto da categoria docente no contexto da pandemia covid-19 |

Kelen Aparecida da Silva Bernardo | Fernanda Landolfi Maia \& Maria Aparecida Bridi

mensagens e até mesmo via redes sociais. A dificuldade da desconexão é outro ponto convergente entre os entrevistados.

Outra questão que atingiu a categoria docente, respeitando as especificidades de cada setor, público ou privado, foram as medidas flexibilizadoras. Observamos que para a categoria docente do setor privado isso é especialmente válido, pois sob o aval do Estado, as escolas-empresas puderam reduzir as jornadas e a remuneração, suspender contratos e outros medidas.

Houve, contudo, nesse processo uma aprendizagem forçada e rápida quanto ao uso de ferramentas de tecnologias informacionais para uma parcela dos docentes. Isto pode representar alterações no período póspandemia. A experiência também pode ter levado a sociedade a uma nova visão sobre o trabalho docente, que esperamos, seja a da revalorização da escola, do ofício docente. Nesse sentido, o desafio ao sindicalismo desta categoria está posto, principalmente para assegurar que as condições precárias de trabalho remoto não perdurem.

\section{Referências:}

ANTUNES, Ricardo. Coronavirus: o trabalho sob fogo cruzado. São Paulo: Boitempo, 2020.

APPLE, Michael W.; KENNETH, Teitelbaun. Está o professorado perdendo o controle de suas qualificações e do currículo? Teoria \& Educação, n. 4, 2003.

BEHAR, Patrícia Alejandra. O Ensino remoto emergencial e a educação a distância. Jornal da Universidade, 6 jul. 2020. Disponivel em https://www.ufrgs.br/coronavirus/base/artigo-o-ensino-remotoemergencial-e-a-educacao-a-distancia. Acesso em: 10 out. 2020.

BERNARDO, Kelen Aparecida da Silva. Flexibilização contratual no setor público: condições e relações de trabalho dos professores temporários nas universidades estaduais do Paraná. Tese (Doutorado em Sociologia) Universidade Federal do Paraná, Curitiba, 2020. Disponível em: https://acervodigital.ufpr.br/handle/1884/67161. Acesso em: 10 out. 2020.

BERNARDO, Kelen Aparecida da Silva. MAIA, Fernanda Landolfi. Banco de Dados Setor Educacional: "Trabalho remoto/home-office no contexto da pandemia COVID-19". Curitiba: GETS/UFPR; REMIR, 2020. 
As configurações do trabalho remoto da categoria docente no contexto da pandemia covid-19 |

Kelen Aparecida da Silva Bernardo | Fernanda Landolfi Maia \& Maria Aparecida Bridi

BRASIL. Decreto n. 9.235, de 15 de dezembro de 2017. Dispõe sobre o exercício das funções de regulação, supervisão e avaliação das instituições de educação superior e dos cursos superiores de graduação e de pósgraduação no sistema federal de ensino. Brasília: Casa Civil, 2017a. Disponivel em: http://www.planalto.gov.br/ccivilo3/Ato20152018/2017/Decreto/D9235.htm. Acesso em: 20 set. 2020.

BRASIL. Instrução normativa $\mathbf{n}^{\circ} \mathbf{6 5}$, de 30 de julho de 2020. Estabelece orientações, critérios e procedimentos gerais a serem observados pelos órgãos e entidades integrantes do Sistema de Pessoal Civil da Administração Federal - SIPEC relativos à implementação de Programa de Gestão. Brasília: Casa Civil, 2020a. Disponivel em: https://www.in.gov.br/en/web/dou//instrucao-normativa-n-65-de-30-de-julhode2020269669395?_ga=2.244737605.1542961348.1602512567775692463.1602084620. Acesso em 29 set. 2020.

BRASIL. Lei n. 13.429, de 31 de março de 2017. Altera dispositivos da Lei n. 6.019, de 3 de janeiro de 1974, que dispõe sobre o trabalho temporário nas empresas urbanas e dá outras providências; e dispõe sobre as relações de trabalho na empresa de prestação de serviços a terceiros. Brasília: Casa Civil, 2017b. Disponivel em: http://www.planalto.gov.br/ccivil_03/_ato2015-2018/2017/lei/113429.htm Acesso em: 12 set. 2010.

BRASIL. Lei n. 13.467, de 13 de julho de 2017. Altera a Consolidação das Leis do Trabalho (CLT), aprovada pelo Decreto-Lei $\mathrm{n}^{\circ} 5.452$, de $1^{\circ}$ de maio de 1943, e as Leis $\mathrm{n}^{\circ}$ 6.019, de 3 de janeiro de 1974, 8.036, de 11 de maio de 1990, e 8.212, de 24 de julho de 1991, a fim de adequar a legislação às novas relações de trabalho. Brasília: Casa Civil, 2017c. Disponivel em: http://www.planalto.gov.br/ccivil_03/_ato2015-

2018/2017/lei/L13467.htm. Acesso em: 28 set. 2020.

BRASIL. Portaria n. 343, de 17 de março de 2020. Dispõe sobre a substituição das aulas presenciais por aulas em meios digitais enquanto durar a situação de pandemia do Novo Coronavirus - COVID-19. Brasília: Casa Civil, 2020b. Disponivel em: https://www.in.gov.br/web/dou//portaria-n-343-de-17-de-marco-de-2020-248564376. Acesso em: 8 set. 2020.

BRASIL. Portaria n. 345, de 19 de Março de 2020. Altera a Portaria MEC $\mathrm{n}^{\circ}$ 343, de 17 de março de 2020c. Brasília: Casa Civil, 2020c. Disponível em: https://pesquisa.in.gov.br/imprensa/jsp/visualiza/index.jsp?jornal=603\&p agina $=1 \&$ data $=19 / 03 / 2020 \&$ totalArquivos $=1$. Acesso em: 8 set. 2020.

BRIDI, Maria Aparecida; BOHLER Fernanda Ribas; ZANONI, Alexandre Pilan. Relatório técnico da pesquisa: Trabalho remoto/home-office no 
As configurações do trabalho remoto da categoria docente no contexto da pandemia covid-19|

Kelen Aparecida da Silva Bernardo | Fernanda Landolfi Maia \& Maria Aparecida Bridi

contexto da pandemia COVID-19. Curitiba: GETS/UFPR; REMIR, 2020. Disponivel em: https://www.eco.unicamp.br/remir/index.php/condicoesde-trabalho/202-o-trabalho-remoto-home-office-no-contexto-da-pandemiacovid-19-parte-ii. Acesso em: 10 out. 2020.

BRIDI, Maria Aparecida. Teletrabalho em tempos de pandemia e condições objetivas que desafiam a classe trabalhadora. São Paulo, 2020 (no prelo).

BRIDI, Maria Aparecida; BRAUNERT, Mariana Bettega; BERNARDO, Kelen Aparecida da Silva. A inserção da precariedade do trabalho no setor público como resultados das políticas neoliberais. In: MELLO, Lawrence Estivalet de; CALDAS, Josiane; GEDIEL, Peres (orgs.). Politicas de austeridade e direitos sociais. 1. ed. Curitiba: Kaygangue, 2019. p. 100-113.

BRIDI, Maria Aparecida; BEZERRA, Giovana UEHARA; ZANONI, Alexandre Pilan. O trabalho remoto e as condições das mulheres no contexto da pandemia COVID-19.

https://jornalggn.com.br/analise/o-trabalho-remoto-e-as-condicoes-dasmulheres-no-contexto-da-pandemia-covid-19/. Acesso em 18 de nov. 2020.

DAL ROSSO, Sadi Dal. Mais trabalho!: a intensificação do labor na sociedade contemporânea. São Paulo: Boitempo, 2008.

FRIGOTTO, Gaudêncio; CIANATTA, Maria; RAMOS, Marise (orgs.) Ensino médio integrado: concepção e contradições. São Paulo: Cortez, 2005.

MACHADO, Sidnei; BRIDI, Maria Aparecida. O teletrabalho no Brasil: a reforma trabalhista de 2017 e o contexto na covid-19, (no prelo)

MAIA, Fernanda Landolfi. O paradoxo da intensificação: uma análise do trabalho dos professores de ensino superior público federal. Tese (Doutorado em Sociologia) - Universidade Federal do Paraná, Curitiba, 2014. Disponivel em: https://acervodigital.ufpr.br/handle/1884/37352. Acesso em: 11 out. 2020.

MAIA, Fernanda Landolfi; BERNARDO, Kelen Aparecida da Silva. O trabalho docente e o setor educacional. In: BRIDI, Maria Aparecida da Cruz (coord.). Relatório técnico da pesquisa: trabalho remoto/home-office no contexto da pandemia COVID-19. Parte II. Curitiba: GETS/UFPR; REMIR, 2020a. Disponivel em: https://www.eco.unicamp.br/remir/index.php/remir-2. Acesso em 18 de outubro de 2020.

MAIA, Fernanda Landolfi; BERNARDO, Kelen Aparecida da Silva. O trabalho remoto/home office no contexto da pandemia COVID-19: um olhar para o setor educacional. In: Rede de Estudos e Monitoramento Interdisciplinar da Reforma Trabalhista (REMIR). 2020b. Disponivel em: https://www.eco.unicamp.br/remir/images/Artigos_2020/TRABALHO_DOC 
ENTE_E_TRABALHO_REMOTO_NA_PANDEMIA_COVID-19_.pdf. Acesso em: 10 out. 2020.

MAIA, Fernanda Landolfi; MULLER, Rodrigo; BERNARDO, Kelen Aparecida da Silva. O trabalho remoto no secretariado: panorama da realidade brasileira a partir do cenário do COVID-19. Revista Expectativa, v. 19, n. 2, p. 118-137, jul./dez., 2020. Disponivel em: $\underline{\text { http://e- }}$ revista.unioeste.br/index.php/expectativa/issue/view/1191/showToc.

Acesso em 10 out. 2020.

MARONESE, Luciane Francielli Zorzetti. A precarização do trabalho docente na Rede Estadual de Educação Básica do Paraná (1995-2002). 2011. Dissertação (Mestrado em Educação) - Universidade Estadual de Maringá, $\quad$ Maringá, 2011. Disponivel em: http://www.ppe.uem.br/SITE\%20PPE\%202010/dissertacoes/2011-

Luciane.pdf. Acesso em: 6 jul. 2018.

MOREIRA, José António Marques; HENRIQUES, Susana; BARROS, Daniela. Transitando de um ensino remoto emergencial para uma educação digital em rede, em tempos de pandemia. Revista Dialogia, n. 34, 2020. Disponível em: $\quad$ https://periodicos.uninove.br/dialogia/article/view/17123/8228. Acesso em: 9 out. 2020.

NAUROSKI, Everson Araújo. Trabalho docente e subjetividade: a condição dos professores temporários (PSS) no Paraná. 2014. 293 f. Tese (Doutorado em Sociologia) - Universidade Federal do Paraná, Curitiba, 2014. Disponível em: https://acervodigital.ufpr.br/handle/1884/38054. Acesso em: 7 out. 2020 .

PITON, Ivania Marini. Politicas educacionais e movimento sindical docente: reformas educativas e conflitos docentes na educação básica paranaense. 2004. 293 f. Tese (Doutorado em Educação) - Universidade Estadual de Campinas, Campinas, 2004. Disponivel em: http://repositorio.unicamp.br/jspui/handle/REPOSIP/253127. Acesso em: 12 out. 2020.

ROSENFIELD, Cinara Lerrer; ALVES, Daniela Alves de. Teletrabalho. In: CATTANI, Antonio David; HOLZMANN, Lorena (orgs.). Dicionário de trabalho e tecnologia. Porto Alegre: Zouk, 2011. p. 414-418.

SENNETT, Richard. A corrosão do caráter. 6. ed. Rio de Janeiro: Record, 2010 .

SOUZA, Marcelo Nogueira de. Condições de trabalho e remuneração docente: o caso do professor temporário na rede estadual de ensino do Paraná. 2011. 202 f. Dissertação (Mestrado em Sociologia) - Universidade 
As configurações do trabalho remoto da categoria docente no contexto da pandemia covid-19 | Kelen Aparecida da Silva Bernardo | Fernanda Landolfi Maia \& Maria Aparecida Bridi

Federal do Paraná, Curitiba, 2011. Disponivel em: https://acervodigital.ufpr.br/handle/1884/25654. Acesso em: 7 out. 2020. 